method, involving distillation after alkaline hydrolysis: the author probably never even considered, let alone tried out, the micro-diffusion technique.

It is in the science rather than in the art of volumetric analysis that Conway has made his other outstanding contribution to the practice of analytical chemistry, namely, in the study of error in volumetric titration, to which the book owes the second part of its title. It is the subject of some 115 pages-nearly one-third of the whole. In the opening eight chapters of the book there are 85 pages devoted to a discussion of the apparatus and principles used in microdiffusion analysis; there also the author has much of value to say on various sources of error that still may go unrecognized.

Discussions of methodology thus occupy a large share of Conway's book-large, anyhow, relative to the space that analysts would have thought appropriate, say, twenty-five year's ago. The influonce of Conway on almost every branch of analytical chemistry is a tribute to the fundamental importance of-and the unseverable connexion between-his theory and practice; there are few authors that can have produced such wide effects with so few words in so short a time. 'The book's 376 pages (excluding references and index) appear modest indeed when compared with the great tomes (at correspondingly great prices) under which the scientist's shelves to-day increasingly groan. Maybe this is in part because the book first appeared only thirteen years ago and has not yet had time to swell unduly. More likely, it seems to me, it is an expression of the rare combination of modesty, logicality and singleness of purpose that caused the author originally to say no more and no less than was absolutely necessary, and to stick to that admirable procedure in both subsequent editions.

The production, printing, paper and binding of the book, its freedom from errors, the clarity of illustrations and graphs, all show an anxiety on the publisher's part to co-operate in the continued success of one of the outstanding scientific monographs of our day. A. L. BACHARACH

\section{FACTS AND SPECULATIONS ABOUT PROTEINS}

Chemistry and Biology of Proteins

By Prof. Felix Haurowitz. Pp. xiit 374. (New York : Academic Press, Inc., 1950.) 5.50 dollars.

$\mathrm{T}$

HE appearance of a new text-book dealing with proteins is bound to be an occasion of great interest to students, teachers and research workers. Each previous effort to deal with this large field has been unsatisfactory in one respect or several, although, taken together, the existing text-books gave a useful synopsis of the literature down to about 1940 . Prof. F. Haurowitz's book was written with graduate students in mind. Such students require from a text-book a connected account of a subject, with key references to monographs and reviews. This they will find. For specialists, too, there is a real mine of references here that will be useful to them, even if they can expect nothing of a comprehensive nature; and there are not many serious errors of substance.

Prof. Haurowitz shows, as those who have followed his experimental work will expect, a real feeling for the obligate relationship of the physical and chemical properties of proteins with their biological functions; the plan of the book reflects this feeling in an original way. After a short section on practical methods for extracting and handling proteins, the evidence is set forth on which modern ideas on the structure of proteins are based. Here an enormous amount of painstaking work by organic chemists is treated very cursorily; there is no reference to the discovery and structural elucidation of the amino-acids, nor to the synthesis and natural occurrence of peptides. On the other hand, much of the physical chemistry is given at considerable length. This is a pity, because previous text-books have shown a similar bias. This factual material is then reconsidered in a discussion on internal structure of globular proteins. The occurrence, properties and biological functions of the various proteins are then surveyed under the following heads: albumins, globulins and other soluble proteins; insoluble proteins (scleroproteins); conjugated proteins; proteins with enzymatic properties; proteins with hormone activity; role of proteins in immunological reactions ; and toxins (toxic proteins). A short section is interpolated on the combination of proteins with other substances.

The next section deals with the supply of aminoacids for protein biosynthesis. Here, perhaps, more evidence would have been acceptable that free amino-acids are actual physiological building-stones for proteins. One feels, also, that too much emphasis, for a broadly biological work of this character, has here been placed on animals, to the exclusion of other organisms that are much more adept at synthesizing amino-acids and consequently of greater interest from this point of view.

The final section, on protein synthesis, is, as Prof. Haurowitz says, speculative. He is doubtful whether nucleic acids can have sufficient specificity to be critically determinant in reproduction. Here many will be with him; cytologists have always been uncritical in claiming importance for those substances that are easy to demonstrate. Prof. Haurowitz suggests that nucleic acids act as stretching agents for holding proteins oriented in a two-dimensional arrangement. Identical two-dimensional protein structures are synthesized on such templates, and then undergo three-dimensional folding which is determined by a variety of other cellular constituents. I find it much harder to picture a 'positive' protein template laying down on itself an identical series of amino-acid residues, as Prof. Haurowitz postulates, than to imagine successive positive-negative-positive interaction of a number of complementary structures as in photography and newspaper printing. Here, at least, we have good analogies from the study of immunology, while in analogy to the positive-positive complementarity Prof. Haurowitz quotes only such events as the crystallization of pure amino-acids from solutions of mixed amino-acids, events which are unusual in the experience of many workers. My feeling is that, as usual in biology, much current speculation will turn out to be gross oversimplification. To treat the 'template' idea as axiomatic is to overrun existing knowledge; it is by no means yet proved that amino-acids are built directly into large proteinlike molecules without passing through a complicated series of intermediate stages.

Taking it as a whole, students will find this book a stimulating supplement to previous text-books, and research workers in all the fields that are concerned with proteins will find in it new and interesting ideas and references.
R. L. M. SYNGE 